\section{Guidelines from the 2017 European Conference on Infections in Leukaemia for management of HHV-6 infection in patients with hematologic malignancies and after hematopoietic stem cell transplantation}

\author{
Katherine N Ward, ${ }^{1}$ Joshua A Hill, ${ }^{2}$ Petr Hubacek, ${ }^{3}$ Rafael de la Camara, ${ }^{4}$ \\ Roberto Crocchiolo, ${ }^{5}$ Hermann Einsele, ${ }^{6}$ David Navarro, ${ }^{7}$ Christine Robin, ${ }^{8}$ \\ Catherine Cordonnier, ${ }^{8}$ and Per Ljungman; ${ }^{9}$ for the 2017 European Conference \\ on Infections in Leukaemia (ECIL)*
}

${ }^{1}$ Division of Infection and Immunity, University College London, London, UK; ${ }^{2}$ Fred Hutchinson Cancer Research Center, Seattle, WA, USA; ${ }^{2}$ Department of Medical Microbiology and Department of Paediatric Haematology and Oncology $2^{\text {nd }}$ Medical Faculty of Charles University and Motol University Hospital, Prague, Czech Republic; ${ }^{4}$ Department of Haematology, Hospital de la Princesa, Madrid, Spain; ${ }^{5}$ SIMT, ASST di Bergamo Ovest, Treviglio, Italy; ${ }^{6}$ Medizinische Klinik und Poliklinik II, Julius Maximilians Universität, Würzburg, Germany; 'Microbiology Service, Hospital Clínico Universitario, Instituto de Investigación INCLIVA and Department of Microbiology, School of Medicine, University of Valencia, Valencia, Spain; ${ }^{8}$ Department of Haematology, Henri Mondor Hospital, Assistance Publique-Hopitaux de Paris, Université Paris-Est Créteil, Créteil, France and ${ }^{9}$ Department of Cellular Therapy and Allogeneic Stem Cell Transplantation, Karolinska University Hospital, Division of Haematology, Department of Medicine Huddinge, Karolinska Institutet, Stockholm, Sweden

${ }^{*} A$ joint project of the European Organization for Research and Treatment of Cancer - Infectious Diseases Group, European Society for Blood and Marrow Transplantation - Infectious Diseases Working Party, European Leukaemia Net-Project 15: Supportive Care and the International Immunocompromised Host Society

\section{ABSTRACT}

$\longrightarrow$ $\mathrm{f}$ the two human herpesvirus 6 (HHV-6) species, human herpesvirus $6 \mathrm{~B}(\mathrm{HHV}-6 \mathrm{~B})$ encephalitis is an important cause of morbidity and mortality after allogeneic hematopoietic stem cell transplant. Guidelines for the management of HHV-6 infections in patients with hematologic malignancies or post-transplant were prepared a decade ago but there have been no other guidelines since then despite significant advances in the understanding of HHV-6 encephalitis, its therapy, and other aspects of HHV-6 disease in this patient population. Revised guidelines prepared at the 2017 European Conference on Infections in Leukaemia covering diagnosis, preventative strategies and management of HHV-6 disease are now presented.

\section{Introduction}

Over the past ten years, it has been recognized that human herpesvirus $6 \mathrm{~A}$ (HHV-6A) and HHV-6B are distinct species, ${ }^{1} \mathrm{HHV}-6 \mathrm{~B}$ not HHV-6A is the most frequent cause of encephalitis post-hematopoietic stem cell transplant (HSCT) and that chromosomally integrated HHV-6 (CIHHV-6) is clinically significant. Revised European Conference on Infections in Leukemia (ECIL) HHV-6 guidelines were prepared after a literature review by a group of experts, and discussed at a plenary session on September 22 nd 2017 until consensus. Those guidelines specifically applying to treatment were graded according to pre-ordained criteria (Table 1) for level of evidence and strength of recommendation; participants were hematologists, microbiologists and infectious disease specialists with expertise on infectious complications in hematology. (A list of ECIL meeting participants is provided in the Online Supplementary Appendix.) A final slide set was posted on the ECIL website (www.ecil-leukaemia.com) on October $2^{\text {nd }}, 2017$ and made available for open consultation.

\section{Ferrata Storti Foundation}

Haematologica 2019

Volume 104(11):2155-2163

\section{Correspondence:}

KATHERINE N WARD

k.n.ward@ucl.ac.uk

Received: April 1, 2019.

Accepted: August 27, 2019.

Pre-published: August 29, 2019.

doi:10.3324/haematol.2019.223073

Check the online version for the most updated information on this article, online supplements, and information on authorship \& disclosures: www.haematologica.org/content/104/11/2155

(C)2019 Ferrata Storti Foundation

Material published in Haematologica is covered by copyright. All rights are reserved to the Ferrata Storti Foundation. Use of published material is allowed under the following terms and conditions:

https://creativecommons.org/licenses/by-nc/4.0/legalcode. Copies of published material are allowed for personal or internal use. Sharing published material for non-commercial purposes is subject to the following conditions:

https://creativecommons. org//icenses/by-nc/4.0/legalcode, sect. 3. Reproducing and sharing published material for commercial purposes is not allowed without permission in writing from the publisher. 


\section{Human herpesvirus $6 \mathrm{~A}$ and human herpesvirus 6B}

The two species of HHV-6, HHV-6A and HHV-6B infect and establish latency in different cell types including CD4 positive $\mathrm{T}$ lymphocytes, monocytes, and other epithelial, fibroblastic and neuronal cells. ${ }^{2}$ No disease has been causally linked to HHV-6A, and its natural history is unknown. In contrast, HHV-6B primary infection is ubiquitous in the first two years of life sometimes causing exanthema subitum; subsequent viral latency gives the potential for reactivation and disease.

\section{Chromosomally integrated human herpesvirus 6}

As well as the almost universal postnatal acquisition of HHV-6B, in approximately $1 \%$ of humans the complete genome of HHV-6A or HHV-6B is integrated into a chromosomal telomere in every nucleated cell in the body and is transmitted through Mendelian inheritance. ${ }^{3,4}$ Although HHV-6A is rare in the general population, HHV-6A and HHV-6B are encountered in approximately one-third and two-thirds of individuals with CIHHV-6, respectively. ${ }^{5}$ Telomeric integration sites have been identified on different chromosomes using fluorescence in situ hybridization (FISH). ${ }^{6}$ Integration is normally restricted to a particular chromosome per individual but very rarely two sites, if inherited from both parents. ${ }^{3}$

Human herpesvirus 6 DNA detected in blood usually indicates virus replication. However, in individuals with CIHHV-6, viral DNA in latent form originating from human chromosomal DNA is persistently detected at high levels in whole blood as well as in "cell free" samples such as serum and cerebrospinal fluid (CSF), since the latter contain cellular DNA released from damaged cells during sample preparation..$^{7.8}$ Although HHV-6B encephalitis is an accepted, albeit rare, complication of primary HHV-6B infection in young children, HHV-6 DNA in the CSF of older immunocompetent children and adults is most likely due to latent virus originating from CIHHV-6 rather than central nervous system (CNS) infection. ${ }^{8,9}$

\section{Chromosomally integrated human herpesvirus 6 and potential for disease post-hematopoietic stem cell transplantation}

There is limited evidence of symptomatic reactivation of CIHHV-6. One report demonstrated CIHHV-6A reacti- vation in a child with severe combined immunodeficiency and hemophagocytic syndrome pre-HSCT and thrombotic microangiopathy post-HSCT. ${ }^{10}$ Two other reports from settings other than HSCT give evidence for symptomatic reactivation in a patient treated with a histone deacetylase inhibitor $^{11}$ and a patient who received a liver transplant from a donor with CIHHV-6A. ${ }^{12}$

Despite the above case of reactivation with accompanying morbidity post-HSCT, ${ }^{10}$ this has not been reported in the few other cases where CIHHV-6 was identified in the donor or recipient, ${ }^{13-16}$ and the frequency and type of diseases caused by CIHHV- 6 in HSCT recipients remain unknown. A recent study of 87 patients with CIHHV-6 in HSCT donors and/or recipients demonstrated an association with acute graft-versus-host disease (GvHD) and cytomegalovirus (CMV) reactivation, but there was no effect on overall or non-relapse mortality. ${ }^{17}$ Neither has an increased frequency of CIHHV-6 been identified in a range of hematologic malignancies. ${ }^{17-21}$ None of these studies was designed to address the likelihood that integration into different chromosomal sites might have different pathological consequences and vary according to HHV-6 species.

\section{Human herpesvirus 6 and disease in patients with hematologic malignancies or post-hematopoietic stem cell transplantation}

In patients with hematologic malignancies without HSCT, there is little evidence that HHV-6 causes disease. Post-HSCT the high frequency of HHV-6B reactivation, plus the difficulty of identifying CIHHV-6, causes substantial challenges in determining the pathogenic role of HHV6 in disease. For autologous transplants, there are insufficient data for a causal association with end-organ disease. However, after allogeneic HSCT, HHV-6B is associated with several syndromes and is a well recognized cause of encephalitis with high morbidity and mortality.

\section{Definitions}

Primary human herpesvirus 6 infection

This is defined as the first detection of HHV-6 replication in an individual with no evidence of previous infec-

Table 1. European Society of Clinical Microbiology and Infectious Diseases (ESCMID) grading system.

\begin{tabular}{ll} 
Strength of a recommendation \\
Grade A & ESCMID strongly supports a recommendation for use \\
Grade B & ESCMID moderately supports a recommendation for use \\
\hline Grade C & ESCMID marginally supports a recommendation for use \\
Grade D & ESCMID supports a recommendation against use \\
\hline
\end{tabular}

\begin{tabular}{|c|c|}
\hline \multicolumn{2}{|c|}{ Quality of evidence } \\
\hline Level I & Evidence from at least one properly designed randomized, controlled trial \\
\hline Level II * & $\begin{array}{l}\text { Evidence from at least one well-designed clinical trial, without randomization; from cohort or case-controlled analytical studies } \\
\text { (preferably from more than one center); from multiple time series; or from dramatic results of uncontrolled experiments }\end{array}$ \\
\hline Level III & $\begin{array}{l}\text { Evidence from opinions of respected authorities, based on clinical experience, descriptive case studies, or reports } \\
\text { of expert committees }\end{array}$ \\
\hline
\end{tabular}

*Added index for level II quality of evidence. $\cdot r$ : meta-analysis or systematic review of randomized controlled trials. $\cdot$ t: transferred evidence, i.e. results from different patient

cohorts, or similar immune-status situation. $\cdot$ h: comparator group is a historical control. $\cdot$ u: uncontrolled trial. $\cdot$ a: published abstract (presented at an international symposium or meeting). 
tion. Normally this would be accompanied by HHV-6 seroconversion, but severely immunocompromised HSCT recipients may not develop antibodies. Donor-derived CIHHV-6 must be excluded.

\section{Human herpesvirus 6 reactivation}

Given the difficulty distinguishing between reactivation of latent virus (endogenous) and reinfection (exogenous), in clinical practice the term HHV-6 reactivation is applied to both scenarios and is defined as new detection of HHV6 in individuals with evidence of previous infection; this latter can be assumed in individuals older than two years. The diagnosis usually relies on the presence of HHV-6 DNA in peripheral blood but other methods and samples are sometimes used. Reactivation is not proven if newly detected HHV-6 DNA is due to donor- or recipientderived CIHHV-6 since latently-integrated viral DNA cannot be distinguished from replicating virus DNA. See below for tests for CIHHV-6 and its reactivation.

\section{Human herpesvirus 6 diagnostic testing}

Antibody tests cannot distinguish between HHV-6A and HHV-6B and are not indicated in HSCT patients. Table 2 gives an overview of possible diagnostic tests.

\section{DNA tests}

Polymerase chain reaction (PCR) is the mainstay of HHV-6 diagnosis and a variety of real-time PCR assays for HHV-6 DNA load are available. ${ }^{22,23}$ Not all differentiate between HHV-6A and HHV-6B, and agreement between laboratories for HHV-6 DNA levels is poor. ${ }^{22,24}$ However, a World Health Organization standard for HHV-6B DNA is now available (http://www.nibsc.org/documents/ ifu/15266.pdf).

- Quantitative PCR that distinguishes between HHV-6A and HHV-6B DNA is recommended for diagnosis of infection.

- For a given patient, repeat HHV-6 DNA testing should be performed using the same DNA extraction method, quantitative PCR and type of specimen.

Interpretation of DNA testing post-hematopoietic stem cell transplantation in the presence of chromosomally integrated human herpesvirus 6

If a HSCT donor has CIHHV-6, HHV-6 DNA load in blood will increase post-HSCT in parallel with leukocyte engraftment, ${ }^{13,16,25}$ and antivirals will have no effect on the quantity of the latently integrated viral DNA. ${ }^{26}$ Alternatively, if the recipient has CIHHV-6, high levels of HHV-6 DNA will be detected pre-HSCT in blood and will decrease alongside recipient leukocytes post-transplant. ${ }^{14,27}$ Importantly, in this latter situation, HHV-6 DNA will continue to be detected at high levels in non-hematopoietic tissue throughout the body ${ }^{28}$ (Table 3).

\section{Tests for chromosomally integrated human herpesvirus 6}

Currently there is no indication for routine testing of HSCT donors or recipients for CIHHV-6. However, in clinically ambiguous cases, such testing can be important

Table 2. Human herpesvirus 6 (HHV-6) diagnostic tests.

\begin{tabular}{ll} 
Method & Use and limitations \\
$\begin{array}{l}\text { Virus culture* } \\
\text { Viral antigen test (immunohistochemical staining)* }\end{array}$ & $\begin{array}{l}\text { Diagnosis of infection: gold standard, specialized, labor-intensive } \\
\text { Diagnosis of infection: limited sensitivity, slow turn-around time }\end{array}$ \\
\hline Detection of viral mRNA by reverse transcription PCR* & $\begin{array}{l}\text { Late gene transcripts to confirm virus replication. No international } \\
\text { standardization or specific thresholds for virus replication, } \\
\text { especially for CIHHV-6 }\end{array}$ \\
Quantitative viral DNA PCR & $\begin{array}{l}\text { Longitudinal studies, comparison of HHV-6 DNA levels in blood } v s . \text { organs. } \\
\text { Can discriminate between HHV-6A and HHV-6B* }\end{array}$ \\
\hline Droplet digital PCR* & $\begin{array}{l}\text { Precise method for DNA levels, identification of CIHHV-6 } \\
\text { Fluorescence } \text { in situ hybridization* }\end{array}$ \\
\hline${ }^{*}$ Not available to most diagnostic laboratories. PCR: polymerase chain reaction; CIHHV-6: chromosomally integrated HHV-6.
\end{tabular}

Table 3. Human herpesvirus 6 (HHV-6) test results after allogeneic hematopoietic stem cell transplantation that indicate naturally acquired HHV6 infection versus chromosomally integrated HHV-6 (CIHHV-6).

\begin{tabular}{|c|c|c|c|c|}
\hline \multirow[t]{2}{*}{ Laboratory observations } & \multicolumn{4}{|c|}{ HHV-6 status } \\
\hline & $\begin{array}{l}\text { Prior childhood } \\
\text { infection* }\end{array}$ & $\begin{array}{l}\text { Donor } \\
\text { CIHHIV-6 positive }\end{array}$ & $\begin{array}{c}\text { Recipient } \\
\text { CIHHV-6 positive }\end{array}$ & $\begin{array}{l}\text { Donor and recipient } \\
\text { CIHHIV-6 positive }\end{array}$ \\
\hline One HHV-6 copy/leukocyte & No & Yes** $^{* *}$ & No & Yes $* *$ \\
\hline One HHV-6 copy/non-hematopoietic cell & No & No & Yes $^{\S}$ & Yes $^{\S}$ \\
\hline HHV-6 species & B & A or B & A or B & A or B \\
\hline Persistent HHV-6 DNA in blood & No & Yes & $+/-* * *$ & Yes \\
\hline Response of HHV-6 DNA level to antiviral drugs & Yes & No & No & No \\
\hline
\end{tabular}

*Human herpesvirus 6B (HHV-6B) primary infection usually occurs in childhood. **HHV-6 found persistently in hematopoietic tissue, e.g. blood, bone marrow, spleen. ${ }^{\text {s }}$ HHV- 6 found persistently at extremely high levels in all nucleated non-hematopoietic cells. ${ }^{* *} \mathrm{~A}$ low level in peripheral blood in cases of organ damage and cell death or hematologic malignancy relapse. 
to avoid unnecessary, potentially toxic, antiviral therapy.

Chromosomally integrated human herpesvirus 6 should be suspected in the donor and/or recipient if HHV-6 DNA detection follows one of the patterns described in Table 3 or if HHV-6A is detected. Where necessary, CIHHV-6 can easily be excluded by a negative HHV-6 DNA test on a blood/serum sample taken pre-transplant from the recipient or at any time from the donor. Individuals with CIHHV-6 have characteristic persistently high levels of HHV-6 DNA in whole blood (>5.5 $\log _{10}$ copies $/ \mathrm{mL}$ ) and in serum (100-fold lower than that in whole blood for a given patient). ${ }^{5,7}$ The level of DNA detected in plasma varies depending on the timing of separation from whole blood. ${ }^{29}$

A ratio of one copy of HHV-6 DNA/cellular genome confirms the diagnosis of CIHHV-6. Droplet digital PCR ${ }^{29}$ is the most accurate method as it gives an absolute number. Comparison of two quantitative real-time PCR results (one for HHV-6 and one for a human gene present in all nucleated cells) is also acceptable albeit with a significant margin of error due to inherent assay imprecision. ${ }^{7} \mathrm{HHV}-$ 6 DNA is present in hair follicles and nails exclusively in persons with CIHHV-6., ${ }^{419}$

- If CIHHV-6 is suspected, whole blood or serum or cellular samples or leftover DNA taken from donor and/or recipient pre-HSCT should be tested by quantitative PCR that distinguishes between HHV-6A and HHV-6B DNA. Testing plasma is not recommended.

- CIHHV-6 can be confirmed by evidence of one copy of viral DNA/cellular genome, or viral DNA in hair follicles/nails, or by FISH demonstrating HHV-6 integrated into a human chromosome.

\section{Tests for chromosomally integrated human herpesvirus 6 reactivation}

This must be confirmed by virus culture plus viral genome sequencing to confirm identity of the viral isolate with the integrated virus.

\section{Human herpesvirus 6B end-organ disease and other outcomes post-hematopoietic stem cell transplantation}

\section{Human herpesvirus 6B primary infection versus reactivation}

Only two cases of primary HHV-6B infection after allogeneic HSCT have been reported; these were in very young children and were accompanied by fever and rash..$^{30,31}$ In contrast, various end-organ diseases and other complications post-HSCT have been associated with HHV-6B reactivation. But apart from encephalitis and fever with rash, the evidence for causation is moderate or weak (Table 4).

\section{Human herpesvirus 6B encephalitis and its definition}

The first described encephalitis case ${ }^{32}$ was followed by many confirmatory reports. ${ }^{33}$ Zerr and Ogata analyzed the accumulated published data and provided evidence for a causal association between HHV-6 and encephalitis using the Bradford Hill criteria. ${ }^{34}$

The most frequent cause of encephalitis after allogeneic transplant is HHV-6. When the species is identified, it is almost invariably HHV-6B. Of the only three reported patients with HHV-6A encephalitis, one had an atypical presentation and the other two had unrecognized CIHHV-6. In one of these two, testing of archived samples confirmed CIHHV-6A pre-HSCT, ${ }^{35}$ but the question remained as to whether reactivation of the virus causing encephalitis or an alternative unidentified cause was responsible. Whether CIHHV-6B can reactivate causing encephalitis is theoretically possible, but requires viral culture and sequencing to distinguish childhood-acquired HHV-6B from integrated virus.

Human herpesvirus $6 \mathrm{~B}$ encephalitis typically presents early as post-transplant acute limbic encephalitis (PALE). CSF protein and cell counts are often unremarkable (see Table 5 for further clinical features). Although magnetic resonance imaging (MRI) may be negative at the start of the disease, changes in the temporal lobe are demonstrated in approximately $60 \%$ of cases. ${ }^{36}$ However, similar observations occur in limbic encephalitis caused by other infectious agents. ${ }^{37}$ Extrahippocampal abnormalities may

Table 4. Human herpesvirus $6 \mathrm{~B}$ reactivation after allogeneic hematopoietic stem cell transplantation: disease associations.

$\begin{array}{cc}\text { Epidemiological associations } & \begin{array}{c}\text { Level of in vitro or in vivo } \\ \text { support for causation }\end{array}\end{array}$

\section{HHV-6B end-organ disease}

\begin{tabular}{lc} 
Encephalitis (predominantly limbic) & Strong \\
$\begin{array}{l}\text { Non-encephalitic central nervous system } \\
\text { dysfunction e.g. delirium, myelitis }\end{array}$ & Moderate \\
\hline $\begin{array}{l}\text { Myelosuppression, allograft failure } \\
\text { Pneumonitis }\end{array}$ & Moderate \\
\hline Hepatitis & Weak \\
\hline
\end{tabular}

\section{Other}

\begin{tabular}{lc} 
Fever and rash & Strong \\
Acute graft-versus-host disease & Moderate \\
\hline CMV reactivation & Moderate \\
Increased all-cause mortality & Weak
\end{tabular}

HHV-6B: human herpesvirus 6B; CMV: cytomegalovirus. Adapted from Table 29.2 in Hill and Zerr. ${ }^{98}$

Table 5. Clinical features of human herpesvirus $6 \mathrm{~B}$ encephalitis.

\begin{tabular}{|c|c|}
\hline Disease onset & Usually 2-6 weeks post HSCT, but can be later \\
\hline Symptoms/signs & $\begin{array}{l}\text { Confusion, encephalopathy, short-term memory } \\
\text { loss, SIADH, seizures, insomnia }\end{array}$ \\
\hline Brain MRI ${ }^{\mathrm{a}}$ & $\begin{array}{l}\text { Often normal. Typically but not exclusively, } \\
\text { circumscribed, non-enhancing, hyperintense } \\
\text { lesions in the medial temporal lobes (especially } \\
\text { hippocampus and amygdala) }\end{array}$ \\
\hline Cerebrospinal fluid & $\begin{array}{l}\text { HHV-6B DNA, +/- mild protein elevation, +/-mild } \\
\text { lymphocytic pleocytosis }\end{array}$ \\
\hline Prognosis & $\begin{array}{l}\text { Memory defects and neuropsychological sequelae } \\
\text { in } 20-60 \% \text {. Death due to progressive encephalitis } \\
\text { in up to } 25 \% \text { of all HSCT recipients and up } \\
\text { to } 50 \% \text { of cord blood recipients }\end{array}$ \\
\hline
\end{tabular}

HSCT: hematopoietic stem cell transplantation; SIADH: syndrome of inappropriate antidiuretic hormone secretion; MRI: magnetic resonance imaging; HHV-6B: human herpesvirus 6B. ${ }^{\mathrm{a}}$ Features of T2, fluid attenuation, inversion recovery (FLAIR) and diffusion weighted-imaging sequences. Modified from Hill and Zerr. ${ }^{99}$ 
occur in areas such as the entorhinal cortex or amygdala. ${ }^{38}$ Temporal lobe seizures are relatively frequent but focal neurological deficits are rare. Computed tomography of the brain is often normal. Electroencephalograms are usually diffusely abnormal sometimes involving the temporal region. Autopsy reveals hippocampal disease with HHV-6 protein in astrocytes and neurons suggesting local virus reactivation ${ }^{32}$ rather than an indirect effect of virally-induced neuroinflammation. Notably, a retrospective study ${ }^{39}$ showed that only one-third of HHV-6 encephalitis patients had the typical features of PALE.

Different studies have used different definitions of HHV-6 encephalitis. ${ }^{40}$ Ideally the definition would require proof of HHV-6 infection in tissue samples from the affected part of the brain. However, given the impracticality of such an approach and the epidemiological evidence, the definition below can replace the need for brain biopsy.

- Diagnosis of HHV-6B encephalitis should be based on HHV-6 DNA in CSF coinciding with acute-onset altered mental status (encephalopathy), or short-term memory loss, or seizures.

- Other likely infectious or non-infectious causes must be excluded.

- CIHHV-6 in donor and recipient should be excluded.

- If CIHHV-6 is detected, evidence for CIHHV-6 reactivation in the CSF or brain tissue is necessary to implicate CIHHV-6.

\section{Other central nervous system dysfunction}

Apart from encephalitis post-HSCT, HHV-6 has been associated with CNS disease ranging from headache to delirium and neurocognitive decline $;^{41-43}$ patients whose donors or recipients had CIHHV-6 were excluded in two of these studies. ${ }^{42,43}$ HHV-6 has also been associated with myelitis, pruritis and dysesthesia in Japanese patients. ${ }^{44}$ Notably, HHV-6 DNA can be found in CSF in patients without CNS symptoms. ${ }^{42}$

\section{Risk factors for human herpesvirus 6B encephalitis}

Human herpesvirus $6 \mathrm{~B}$ reactivation in blood (i.e. viremia) is a major risk factor and occurs in approximately half of allogeneic transplant recipients in the first few weeks post-HSCT. ${ }^{45,46}$ The highest rates are seen after umbilical cord blood transplantation (CBT); in a prospective cohort of 125 cord blood recipients, HHV-6B reactivation was documented in $94 \% .^{47}$ In a multicenter prospective study, Ogata et al ${ }^{48}$ showed that reactivation precedes or coincides with HHV-6 encephalitis and that $\geq 10,000$ copies $/ \mathrm{mL}$ in plasma correlated with onset of disease with $100 \%$ sensitivity and $64.6 \%$ specificity. Similar values of $100 \%$ and $81 \%$ respectively were obtained in a much larger retrospective study. ${ }^{49}$

However, not all patients develop encephalitis when the plasma HHV-6 DNA level is high, and other factors are involved, usually related to poor $\mathrm{T}$-cell function, such as T-cell depleted allografts, CBT, a mismatched or unrelated donor, acute GvHD and treatment with glucocorticoids. ${ }^{50}$ A retrospective cohort study of 1,344 patients showed CBT is a major risk factor [adjusted hazard ratio (aHR) 20.0; $P<0.001$ ], as well as acute GvHD grades II-IV (aHR 7.5; $P<0.001$ ) and use of mismatched unrelated donors (aHR 4.3; $P<0.04){ }^{49}$ A subsequent systematic review and meta-analysis of all relevant HSCT studies also demonstrated the incidence of HHV-6 encephalitis was significantly higher post-CBT than other stem cell sources $(8.3 \%$ vs. $0.5 \% ; P<0.001) .{ }^{40}$ Ogata et al..$^{36}$ used the Japanese Adult Transplant Registry and identified 145 patients with $\mathrm{HHV}-6$ encephalitis; the relative risk for CBT was $11.09(P<0.001)$ and $9.48(P<0.001)$ for HLAmismatched unrelated donors. Haploidentical transplant recipients may also be at high risk of HHV-6B encephalitis based on a combined report of two small studies ${ }^{51}$ where, in an attempt to improve engraftment and reduce GvHD, donor cells were depleted of naïve T cells and natural killer (NK) cells, but memory $\mathrm{T}$ cells remained. Finally, pre-engraftment syndrome might be a risk factor for HHV-6 encephalitis. ${ }^{50}$

\section{Prognosis of human herpesvirus 6B encephalitis}

Zerr $^{33}$ reviewed the outcome in the many previous detailed descriptions of individual patients; 11 of 44 $(25 \%)$ died within 1-4 weeks of diagnosis, $6(14 \%)$ showed improvement but died with various unrelated medical problems, 8 (18\%) improved but with lingering neurological compromise, and 19 (43\%) appeared to make a full recovery. In a single retrospective study, Hill et al. ${ }^{49}$ reported 19 patients with PALE; attributable mortality was higher after CBT (5 of 10) than in recipients of adult donor stem cells (0 of 9 ). In a much larger number of allogeneic HSCT recipients, ${ }^{36}$ neuropsychological sequelae were reported in $57 \%$ of encephalitic patients with an overall survival rate of $58.3 \%$ in those with encephalitis as opposed to $80.5 \%$ in those without.

Other retrospective surveys of small numbers of patients have reported variable outcomes in terms of mortality and neurological sequelae including temporal lobe epilepsy (TLE). ${ }^{50}$ Long-term consequences of HHV-6 encephalitis post-HSCT in children may include a new syndrome, involving generalized epilepsy (as opposed to TLE in adults) together with cognitive regression and delayed intellectual development. . 2,53

\section{Human herpesvirus 6B myelosuppression and allograft failure}

Evidence for a causal association is moderate (Table 4). HHV-6B infects hematologic progenitor cells in vitro thereby reducing colony formation. ${ }^{54}$ Virus reactivation postHSCT has been frequently associated with myelosuppression and delayed engraftment, particularly involving platelets ${ }^{46,55,56}$ and also allograft failure..$^{57,58}$

- If there is failed engraftment, blood or bone marrow should be tested for HHV-6B DNA.

- Other likely infectious or non-infectious causes must be excluded.

- CIHHV-6 in donor and recipient should be excluded.

\section{Other end-organ diseases}

Evidence for a causal association of HHV-6 with other disease post-HSCT is weak (Table 4). Viral DNA in tissue is not diagnostic as it may reflect HHV-6 DNAemia or inflammation with consequent infiltrating HHV-6 infected lymphocytes.

Pneumonitis remains a leading cause of morbidity and mortality post-HSCT, and HHV-6 has been implicated as a potential cause. ${ }^{59}$ Studies using heterogeneous populations and methods, including patients with hematologic malignancies with and without HSCT, have produced variable results. ${ }^{60-62}$ A recent study applied molecular testing for 28 pathogens in bronchoalveolar lavage samples 
from HSCT recipients previously diagnosed with idiopathic pneumonia syndrome. HHV-6 was the most common pathogen (29\% of cases) identified, and it was the only pathogen in approximately half of these ${ }^{63}$ However, the clinical significance of this finding remains to be determined.

Although there are many reports of HHV-6B-associated hepatitis after liver transplantation, this has only been well documented in two cases post-HSCT, ${ }^{64,65}$ both of which describe acute hepatitis successfully treated with ganciclovir. HHV-6B DNA was demonstrated in hepatic tissue by immunohistochemistry.

- In suspected end-organ disease other than failed engraftment or encephalitis, tissue from the affected organ should be tested for HHV-6 infection by culture, immunochemistry, in situ hybridization or reverse transcription PCR for mRNA.

- PCR for HHV-6 DNA in tissue is not recommended for documentation of HHV-6 disease.

- Other likely infectious or non-infectious causes must be excluded.

- CIHHV-6 in donor and recipient should be excluded.

\section{Human herpesvirus 6B and cytomegalovirus reactivation}

Human herpesvirus $6 \mathrm{~B}$ reactivation has been associated with an increased risk of subsequent CMV reactivation and disease post-HSCT, 45,66 although this was not replicated in another study. ${ }^{67}$ One study suggests that HHV-6 reactivation may indicate cellular immunosuppression which also predisposes to $\mathrm{CMV}$ reactivation. ${ }^{68}$ In vitro studies of HHV-6 reactivation demonstrate that HHV-6B infection might contribute to $\mathrm{CMV}$ reactivation through inhibition of IL-12 production. ${ }^{69,70}$

\section{Human herpesvirus 6B - acute graft-versus-host disease and increased all-cause mortality}

A well-designed study established an association between HHV-6B reactivation and subsequent acute GvHD. ${ }^{71} \mathrm{~A}$ meta-analysis of 11 such studies demonstrated a statistically significant association between HHV-6B and subsequent grade II-IV acute GvHD (HR: 2.65; 95\% CI: 1.89-3.72; $P<0.001) .{ }^{72}$

Human herpesvirus $6 \mathrm{~B}$ reactivation has also been associated with increased all-cause mortality postHSCT. ${ }^{45,46,73,74}$ However, whether HHV-6B directly or indirectly impacts on mortality in the absence of clinically apparent end-organ disease remains unclear.

\section{Treatment strategies}

\section{Antiviral drugs and immunotherapy}

Ganciclovir, foscarnet, and cidofovir inhibit HHV-6 replication in vitro. ${ }^{75}$ Whilst in vitro studies support the potential for HHV-6 to develop resistance to the above antiviral agents, very few case reports have described the emergence of drug-resistant isolates, specifically to ganciclovir, and after lengthy exposure in the clinical setting. ${ }^{76-}$ 79 Additionally, the use of valganciclovir or ganciclovir treatment for CMV disease did not result in the emergence of drug-resistant HHV-6 mutants in a large prospective trial of solid organ transplant patients. ${ }^{80}$

New treatment modalities for HHV-6 are needed due to the nephrotoxic and myelosuppressive properties of the available agents. Brincidofovir (or CMX-001) has high in vitro activity against HHV-6 species ${ }^{81}$ but has significant gastrointestinal toxicity; ${ }^{32}$ an intravenous formulation under development may be better tolerated. ${ }^{83}$ However, this drug is not currently available for clinical use. Adoptive immunotherapy with virus-specific $T$ cells is an exciting new therapeutic approach for HHV- $6 .{ }^{84,85}$ This approach appears to be safe and potentially effective in small, uncontrolled studies.

\section{Prevention of human herpesvirus 6B encephalitis}

Human herpesvirus $6 \mathrm{~B}$ DNA screening during the highrisk period post-HSCT is impractical as HHV-6 reactivation often coincides with the onset of disease ${ }^{48}$ Effective pre-emptive or prophylactic strategies have not been identified. Three prospective, non-randomized studies of prophylactic foscarnet (pre- or post-engraftment) did not significantly lower the incidence of encephalitis. ${ }^{86-88}$ Similarly, two prospective, non-randomized studies of pre-emptive ganciclovir or foscarnet did not reduce the incidence of HHV-6B encephalitis. ${ }^{89,90}$ Failure of these approaches may be a result of inadequate dosing due to concerns about toxicity and resultant insufficient drug penetration into the CSF. Thus, routine HHV-6 DNA screening is not recommended for pre-emptive or prophylactic therapy, in any context.

- Routine screening of HHV-6 DNA in blood postHSCT is not recommended (DIIu)

- Anti-HHV-6 prophylactic or pre-emptive therapy is not recommended for the prevention of HHV-6B reactivation or encephalitis post-HSCT (DIIu)

\section{Treatment of human herpesvirus 6B encephalitis}

Zerr et al. ${ }^{91}$ demonstrated a response of HHV-6 to ganciclovir or foscarnet as measured by DNA in the CSF or serum of allogeneic HSCT patients. Ljungman et al. ${ }^{92}$ reported reductions in the HHV-6 load in saliva in patients receiving ganciclovir for pre-emptive therapy of CMV. Vu et al. ${ }^{93}$ described positive responses in 4 of 5 patients treated with foscarnet.

On the basis of the above results, foscarnet or ganciclovir were recommended for treatment of HHV-6 encephalitis post-HSCT. ${ }^{94}$ Since then a substantial amount of additional evidence supports the use of ganciclovir and foscarnet. Hill et al. ${ }^{49}$ treated 18 patients with HHV-6 PALE with foscarnet $180 \mathrm{mg} / \mathrm{kg} /$ day and symptoms improved in most. Schmidt-Hieber et al..$^{95}$ reported a response rate of $63 \%$ with either foscarnet or ganciclovir therapy for HHV-6 encephalitis. More recently, data comparing the use of ganciclovir with foscarnet in Japanese patients ${ }^{36}$ showed response rates of neurological symptoms were $83.8 \%$ and $71.4 \%$ with foscarnet monotherapy and ganciclovir monotherapy, respectively ( $P=0.10$, Fisher's exact test). Full-dose therapy with foscarnet $(\geq 180 \mathrm{mg} / \mathrm{kg})$ or ganciclovir $(\geq 10 \mathrm{mg} / \mathrm{kg})$ was associated with a better response rate than treatment with lower doses (foscarnet, 93\% vs. 74\%, $P=0.044$; ganciclovir, $84 \%$ vs. $58 \%, P=0.047)$. The response rate of ten patients receiving combination therapy with various doses of foscarnet and ganciclovir was 100\%. However, the small sample size limits conclusions regarding whether combination therapy is superior to monotherapy, and drug toxicity is an important consideration. Death from any cause within 30 days after development of HHV-6 encephalitis was significantly lower in patients 
who received foscarnet and significantly higher in patients who received ganciclovir, but this was in unadjusted descriptive analyses.

Information on the clinical use of cidofovir for the treatment of HHV-6 encephalitis is limited to two case reports; ${ }^{96,97}$ in one cidofovir was interrupted due to drug toxicity and in the other the drug was combined with foscarnet.

- Intravenous foscarnet or ganciclovir are recommended for treatment of HHV-6B encephalitis. Drug selection should be dictated by the drug's side effects and the patient's comorbidities (AIIu).

- The recommended doses are $90 \mathrm{mg} / \mathrm{kg}$ b.d. for foscarnet and $5 \mathrm{mg} / \mathrm{kg}$ b.d. for ganciclovir (AIIu).

- Antiviral therapy should be for at least three weeks and until testing demonstrates clearance of HHV-6 DNA from blood and, if possible, CSF (CIII).

- Combined ganciclovir and foscarnet therapy can be considered (CIII).

- Immunosuppressive medications should be reduced if possible (BIII).

- There are insufficient data on the use of cidofovir to make a recommendation.

\section{Treatment of human herpesvirus 6B associated end-organ diseases other than encephalitis}

Since the strength of associations with other end-organ diseases is moderate or weak, there are insufficient data to guide a recommendation for antiviral treatment.

- No recommendation can be made.

\section{Conclusions}

Human herpesvirus $6 \mathrm{~B}$ is the primary cause of infectious encephalitis after allogeneic HSCT. Studies of prevention and treatment strategies for this disease are urgently required to improve outcomes using novel therapeutic approaches, such as new antiviral drugs and immunotherapy.

As regards other possible HHV-6B end-organ diseases post-HSCT, improved RNA diagnostic tests are necessary to demonstrate active viral replication (in situ hybridization and/or reverse transcription PCR).

Understanding the pathogenic potential of HHV-6 and CIHHV-6 requires that all prospective studies on HSCT patients and health outcomes use tests on both donor and recipient that distinguish HHV-6A from HHV-6B.

\section{Funding}

The ECIL meeting (Sept 21-23, 2017) was supported by unrestricted grants from Astellas, Basilea, Chimerix, Clinigen, Gilead, MSD, Pfizer and Shire. None of these pharmacentical companies had any role in the selection of experts and the scope and purpose of the guidelines, or the collection, analysis, and interpretation of the data and editing the guidelines.

\section{Acknowledgments}

The authors would like to thank Thierry Calandra for chairing the ECIL HHV-6 session and the ECIL participants. We also thank GL events, Lyon, France for organizing the meeting.

\section{References}

1. Ablashi D, Agut $\mathrm{H}$, Alvarez-Lafuente $\mathrm{R}$, et al. Classification of HHV-6A and HHV-6B as distinct viruses. Arch Virol. 2014;159(5):863870.

2. De Bolle L, Naesens L, De Clercq E. Update on human herpesvirus 6 biology, clinical features, and therapy. Clin Microbiol Rev. 2005;18(1):217-245.

3. Daibata M, Taguchi T, Nemoto Y, Taguchi $\mathrm{H}$, Miyoshi I. Inheritance of chromosomally integrated human herpesvirus 6 DNA. Blood. 1999;94(5):1545-1549.

4. Tanaka-Taya K, Sashihara J, Kurahashi H, et al. Human herpesvirus 6 (HHV-6) is transmitted from parent to child in an integrated form and characterization of cases with chromosomally integrated HHV-6 DNA. J Med Virol. 2004;73(3):465-473.

5. Pellett PE, Ablashi DV, Ambros PF, et al. Chromosomally integrated human herpesvirus 6: questions and answers. Rev Med Virol. 2012;22(3):144-155

6. Nacheva EP, Ward KN, Brazma D, et al. Human herpesvirus 6 integrates within telomeric regions as evidenced by five different chromosomal sites. J Med Virol. 2008;80(11):1952-1958.

7. Ward KN, Leong HN, Nacheva EP, et al. Human herpesvirus 6 chromosomal integration in immunocompetent patients results in high levels of viral DNA in blood, sera, and hair follicles. J Clin Microbiol. 2006;44(4):1571-1574.

8. Ward $\mathrm{KN}$, Leong $\mathrm{HN}$, Thiruchelvam $\mathrm{AD}$,
Atkinson CE, Clark DA. Human herpesvirus 6 DNA levels in cerebrospinal fluid due to primary infection differ from those due to chromosomal viral integration and have implications for diagnosis of encephalitis. Clin Microbiol. 2007;45(4):1298-1304

9. Ward KN. Child and adult forms of human herpesvirus 6 encephalitis: looking back, looking forward. Curr Opin Neurol. 2014;27(3):349-355.

10. Endo A, Watanabe $K$, Ohye $T$, et al. Molecular and virological evidence of viral activation from chromosomally integrated human herpesvirus $6 \mathrm{~A}$ in a patient with $\mathrm{X}$ linked severe combined immunodeficiency. Clin Infect Dis. 2014:59(4):545-548.

11. Politikos I, McMasters M, Bryke C, Avigan D, Boussiotis VA. Possible reactivation of chromosomally integrated human herpesvirus 6 after treatment with histone deacetylase inhibitor. Blood Adv. 2018;2 (12):1367-1370

12. Bonnafous P, Marlet J, Bouvet D, et al. Fatal outcome after reactivation of inherited chromosomally integrated HHV-6A (iciHHV-6A) transmitted through liver transplantation. Am J Transplant. 2018;18(6):1548-1551.

13. Clark DA, Nacheva EP, Leong HN, et al Transmission of integrated human herpesvirus 6 through stem cell transplantation: implications for laboratory diagnosis. J Infect Dis. 2006;193(7):912-916.

14. Hubacek P, Hyncicova K, Muzikova K, Cinek O, Zajac M, Sedlacek P. Disappearance of pre-existing high HHV-6 DNA load in blood after allogeneic SCT. Bone Marrow Transplant. 2007;40(8):805806.
15. Yagasaki H, Shichino H, Shimizu N, et al. Nine-year follow-up in a child with chromosomal integration of human herpesvirus 6 transmitted from an unrelated donor through the Japan Marrow Donor Program. Transpl Infect Dis. 2015;17(1):160-161.

16. Yamada $Y$, Osumi $\mathrm{T}$, Imadome KI, et al Transmission of chromosomally integrated human herpesvirus 6 via cord blood transplantation. Transpl Infect Dis. 2017;19 (1):e12636.

17. Hill JA, Magaret AS, Hall-Sedlak R, et al. Outcomes of hematopoietic cell transplantation using donors or recipients with inherited chromosomally integrated HHV-6. Blood. 2017;130(8):1062-1069

18. Hubacek P, Muzikova K, Hrdlickova A, et al. Prevalence of HHV-6 integrated chromosomally among children treated for acute lymphoblastic or myeloid leukemia in the Czech Republic. J Med Virol. 2009;81(2): 258-263.

19. Hubacek P, Hrdlickova A, Spacek M, et al. Prevalence of chromosomally integrated HHV-6 in patients with malignant disease and healthy donors in the Czech Republic. Folia Microbiol (Praha). 2013;58(1):87-90.

20. Gravel A, Sinnett D, Flamand L. Frequency of chromosomally-integrated human herpesvirus 6 in children with acute lymphoblastic leukemia. PLoS One. 2013;8(12): e84322.

21. Bell AJ, Gallagher A, Mottram T, et al. Germ-line transmitted, chromosomally integrated HHV- 6 and classical Hodgkin lymphoma. PLoS One. 2014;9(11):e112642.

22. Flamand L, Gravel A, Boutolleau D, et al Multicenter comparison of PCR assays for 
detection of human herpesvirus 6 DNA in serum. J Clin Microbiol. 2008;46(8):27002706.

23. Cassina G, Russo D, De BD, Broccolo F, Lusso P, Malnati MS. Calibrated real-time polymerase chain reaction for specific quantitation of HHV-6A and HHV-6B in clinical samples. J Virol Methods. 2013;189(1):172179

24. de Pagter PJ, Schuurman R, de Vos NM, Mackay W, van Loon AM. Multicenter external quality assessment of molecular methods for detection of human herpesvirus 6. J Clin Microbiol. 2010;48(7):2536-2540.

25. Purev E, Winkler T, Danner RL, et al. Engraftment of donor cells with germ-line integration of HHV6 mimics HHV6 reactivation following cord blood/haplo transplantation. Blood. 2014;124(7):1198-1199.

26. Hubacek P, Maalouf J, Zajickova M, et al. Failure of multiple antivirals to affect high HHV-6 DNAaemia resulting from viral chromosomal integration in a case of severe aplastic anaemia. Haematologica. 2007;92 (10):e98-e100.

27. Jeulin H, Guery M, Clement L, et al. Chromosomally integrated HHV-6: slow decrease of HHV-6 viral load after hematopoietic stem-cell transplantation. Transplantation. 2009;88(9):1142-1143.

28. Hubacek P, Virgili A, Ward KN, et al. HHV-6 DNA throughout the tissues of two stem cell transplant patients with chromosomally integrated HHV-6 and fatal CMV pneumonitis. Br J Haematol. 2009;145(3):394398.

29. Sedlak RH, Cook L, Huang ML, et al. Identification of chromosomally integrated human herpesvirus 6 by droplet digital PCR. Clin Chem. 2014:60(5):765-772.

30. Lau YL, Peiris M, Chan GC, Chan AC, Chiu D, Ha SY. Primary human herpes virus 6 infection transmitted from donor to recipient through bone marrow infusion. Bone Marrow Transplant. 1998;21(10):1063-1066.

31. Muramatsu $\mathrm{H}$, Watanabe $\mathrm{N}$, Matsumoto K, et al. Primary infection of human herpesvirus-6 in an infant who received cord blood SCT. Bone Marrow Transplant. 2009;43(1):83-84

32. Drobyski WR, Knox KK, Majewski D, Carrigan DR. Brief report: fatal encephalitis due to variant B human herpesvirus- 6 infection in a bone marrow-transplant recipient. N Engl J Med. 1994;330(19):1356-1360.

33. Zerr DM. Human herpesvirus 6 and central nervous system disease in hematopoietic cell transplantation. J Clin Virol. 2006;37 Suppl 1:S52-S56.

34. Zerr DM, Ogata M. HHV-6A and HHV-6B in Recipients of Hematopoietic Cell Transplantation. In: Flamand L, Lautenschlager I, Krueger G, Ablashi D, editors. HHV-6A, HHV-6B \& HHV-7 Diagnosis and Clinical Management. 3rd ed. San Francisco: Elsevier; 2014.

35. Hill JA, Sedlak RH, Zerr DM, et al. Prevalence of chromosomally integrated human herpesvirus 6 in patients with human herpesvirus 6-central nervous system dysfunction. Biol Blood Marrow Transplant. 2015;21(2):371-373

36. Ogata M, Oshima K, Ikebe T, et al. Clinical characteristics and outcome of human herpesvirus-6 encephalitis after allogeneic hematopoietic stem cell transplantation. Bone Marrow Transplant. 2017;52(11):15631570.

37. Noguchi T, Yoshiura T, Hiwatashi A, et al. CT and MRI findings of human herpesvirus 6-associated encephalopathy: comparison with findings of herpes simplex virus encephalitis. AJR Am J Roentgenol. 2010; 194(3):754-760

38. Provenzale JM, van LK, White LE. Clinical and imaging findings suggesting human herpesvirus 6 encephalitis. Pediatr Neurol. 2010;42(1):32-39.

39. Bhanushali MJ, Kranick SM, Freeman AF, et al. Human herpes 6 virus encephalitis complicating allogeneic hematopoietic stem cell transplantation. Neurology. 2013;80(16): 1494-1500.

40. Scheurer ME, Pritchett JC, Amirian ES Zemke NR, Lusso P, Ljungman P. HHV-6 encephalitis in umbilical cord blood transplantation: a systematic review and metaanalysis. Bone Marrow Transplant. 2013;48 (4):574-580

41. Zerr DM, Fann JR, Breiger D, et al. HHV-6 reactivation and its effect on delirium and cognitive functioning in hematopoietic cell transplantation recipients. Blood. 2011;117 (19):5243-5249.

42. Hill JA, Boeckh MJ, Sedlak RH, Jerome KR, Zerr DM. Human herpesvirus 6 can be detected in cerebrospinal fluid without associated symptoms after allogeneic hematopoietic cell transplantation. J Clin Virol. 2014;61(2):289-292.

43. Hill JA, Boeckh M, Leisenring WM, et al. Human herpesvirus $6 \mathrm{~B}$ reactivation and delirium are frequent and associated events after cord blood transplantation. Bone Marrow Transplant. 2015:50(10):1348-1351.

44. Ueki T, Hoshi K, Hiroshima Y, et al. Analysis of five cases of human herpesvirus- 6 myelitis among 121 cord blood transplantations. Int J Hematol. 2018;107(3):363-372.

45. Zerr DM, Boeckh M, Delaney C, et al. HHV6 reactivation and associated sequelae after hematopoietic cell transplantation. Biol Blood Marrow Transplant. 2012;18(11) 1700-1708.

46. Dulery R, Salleron J, Dewilde A, et al. Early human herpesvirus type 6 reactivation after allogeneic stem cell transplantation: a largescale clinical study. Biol Blood Marrow Transplant. 2012;18(7):1080-1089

47. Olson AL, Dahi PB, Zheng J, et al. Frequent human herpesvirus- 6 viremia but low incidence of encephalitis in double-unit cord blood recipients transplanted without antithymocyte globulin. Biol Blood Marrow Transplant. 2014;20(6):787-793.

48. Ogata M, Satou T, Kadota I, et al. Human herpesvirus 6 (HHV-6) reactivation and HHV-6 encephalitis after allogeneic hematopoietic cell transplantation: a multicenter, prospective study. Clin Infect Dis. 2013;57(5):671-681

49. Hill JA, Koo S, Guzman Suarez BB et al. Cord-blood hematopoietic stem cell transplant confers an increased risk for human herpesvirus-6-associated acute limbic encephalitis: a cohort analysis. Biol Blood Marrow Transplant. 2012;18(11):1638-1648

50. Ogata M, Fukuda T, Teshima T. Human her pesvirus-6 encephalitis after allogeneic hematopoietic cell transplantation: what we do and do not know. Bone Marrow Transplant 2015; 50(8):1030-1036

51. Perruccio K, Sisinni L, Perez-Martinez A, et al. High Incidence of Early Human Herpesvirus-6 Infection in Children Undergoing Haploidentical Manipulated Stem Cell Transplantation for Hematologic Malignancies. Biol Blood Marrow Transplant. 2018;24(12):2549-2557.

52. Howell KB, Tiedemann K, Haeusler G, et al. Symptomatic generalized epilepsy after HHV6 posttransplant acute limbic encephalitis in children. Epilepsia. 2012;53 (7):e122-e126

53. Raspall-Chaure M, Armangue T, Elorza I, Sanchez-Montanez A, Vicente-Rasoamalala M, Macaya A. Epileptic encephalopathy after HHV6 post-transplant acute limbic encephalitis in children: confirmation of a new epilepsy syndrome. Epilepsy Res. 2013;105(3):419-422.

54. Isomura $\mathrm{H}$, Yoshida $\mathrm{M}$, Namba $\mathrm{H}$, et al Suppressive effects of human herpesvirus-6 on thrombopoietin-inducible megakaryocytic colony formation in vitro. J Gen Virol. 2000;81(Pt 3):663-673.

55. Ljungman P, Wang FZ, Clark DA, et al. High levels of human herpesvirus 6 DNA in peripheral blood leucocytes are correlated to platelet engraftment and disease in allogeneic stem cell transplant patients. $\mathrm{Br} J$ Haematol. 2000;111(3):774-781

56. Zerr DM, Corey L, Kim HW, Huang ML, Nguy L, Boeckh M. Clinical outcomes of human herpesvirus 6 reactivation after hematopoietic stem cell transplantation. Clin Infect Dis. 2005;40(7):932-940.

57. Lagadinou ED, Marangos M, Liga $M$, et al. Human herpesvirus 6-related pure red cell aplasia, secondary graft failure, and clinical severe immune suppression after allogeneic hematopoietic cell transplantation successfully treated with foscarnet. Transpl Infect Dis. 2010;12(5):437-440.

58. Le Bourgeois A, Labopin M, Guillaume T, et al. Human herpesvirus 6 reactivation before engraftment is strongly predictive of graft failure after double umbilical cord blood allogeneic stem cell transplantation in adults. Exp Hematol. 2014;42(11):945-954.

59. Carrigan DR, Drobyski WR, Russler SK Tapper MA, Knox KK, Ash RC. Interstitia pneumonitis associated with human herpesvirus-6 infection after marrow transplantation. Lancet. 1991;338(8760):147-149.

60. Cone RW, Hackman RC, Huang ML, et al Human herpesvirus 6 in lung tissue from patients with pneumonitis after bone marrow transplantation. N Engl J Med. 1993; 329(3):156-161

61. Buchbinder S, Elmaagacli AH, Schaefer UW, Roggendorf M. Human herpesvirus 6 is an important pathogen in infectious lung disease after allogeneic bone marrow transplantation. Bone Marrow Transplant. 2000;26(6):639-644.

62. Nishimaki K, Okada S, Miyamura $K$, et al The possible involvement of human her pesvirus type 6 in obliterative bronchiolitis after bone marrow transplantation. Bone Marrow Transplant. 2003;32(11):1103-1105.

63. Seo S, Renaud C, Kuypers JM, et al Idiopathic pneumonia syndrome after hematopoietic cell transplantation: evidence of occult infectious etiologies. Blood 2015;125(24):3789-3797.

64. Hill JA, Myerson D, Sedlak RH, Jerome KR, Zerr DM. Hepatitis due to human herpesvirus $6 \mathrm{~B}$ after hematopoietic cell transplantation and a review of the literature. Transpl Infect Dis. 2014;16(3):477-483.

65. Kuribayashi K, Matsunaga T, Iyama S, et al. Human herpesvirus- 6 hepatitis associated with cyclosporine-A encephalitis after bone marrow transplantation for chronic myeloid leukemia. Intern Med. 2006;45(7): 475-478.

66. Crocchiolo R, Giordano L, Rimondo A, et al Human Herpesvirus 6 replication predicts Cytomegalovirus reactivation after allogeneic stem cell transplantation from haploidentical donor. J Clin Virol. 2016;84: 24-26.

67. Tormo N, Solano C, de la Camara R, et al An assessment of the effect of human her 
pesvirus-6 replication on active cytomegalovirus infection after allogeneic stem cell transplantation. Biol Blood Marrow Transplant. 2010;16(5):653-661.

68. Wang FZ, Larsson K, Linde A, Ljungman P. Human herpesvirus 6 infection and cytomegalovirus-specific lymphoproliferative responses in allogeneic stem cell transplant recipients. Bone Marrow Transplant. 2002;30(8):521-526.

69. Smith AP, Paolucci C, Di Lullo G, Burastero SE, Santoro F, Lusso P. Viral replication-independent blockade of dendritic cell maturation and interleukin-12 production by human herpesvirus 6. J Virol. 2005;79(5): 2807-2813.

70. Lusso P. HHV-6 and the immune system: mechanisms of immunomodulation and viral escape. J Clin Virol. 2006; 37 Suppl 1:S4-10.

71. Admiraal R, de Koning $\mathrm{CCH}$, Lindemans $\mathrm{CA}$, et al. Viral reactivations and associated outcomes in the context of immune reconstitution after pediatric hematopoietic cell transplantation. J Allergy Clin Immunol. 2017;140(6):1643-1650.

72. Phan TL, Carlin K, Ljungman P, et al. Human Herpesvirus-6B Reactivation Is a Risk Factor for Grades II to IV Acute Graft-versus-Host Disease after Hematopoietic Stem Cell Transplantation: A Systematic Review and Meta-Analysis. Biol Blood Marrow Transplant. 2018;24(11):2324-2336.

73. de Pagter PJ, Schuurman R, Visscher H, et al. Human herpes virus 6 plasma DNA positivity after hematopoietic stem cell transplantation in children: an important risk factor for clinical outcome. Biol Blood Marrow Transplant. 2008;14(7):831-839.

74. Hill JA, Mayer BT, Xie H, et al. Kinetics of Double-Stranded DNA Viremia After Allogeneic Hematopoietic Cell Transplantation. Clin Infect Dis. 2018;66(3):368-375.

75. Prichard MN, Whitley RJ. The development of new therapies for human herpesvirus 6 . Curr Opin Virol. 201;9:148-153.

76. Manichanh C, Olivier-Aubron C, Lagarde JP, et al. Selection of the same mutation in the U69 protein kinase gene of human herpesvirus- 6 after prolonged exposure to ganciclovir in vitro and in vivo. J Gen Virol. 2001;82(Pt 11):2767-2776.

77. Isegawa Y, Hara J, Amo K, et al. Human herpesvirus 6 ganciclovir-resistant strain with amino acid substitutions associated with the death of an allogeneic stem cell transplant recipient. J Clin Virol. 2009;44(1):15-19.

78. Baldwin K. Ganciclovir-resistant human herpesvirus-6 encephalitis in a liver transplant patient: a case report. J Neurovirol. 2011;17 (2):193-195.
79. Piret J, Boivin G. Antiviral drug resistance in herpesviruses other than cytomegalovirus. Rev Med Virol. 2014:24(3):186-218.

80. Bounaadja L, Piret J, Goyette N, Boivin G. Analysis of HHV-6 mutations in solid organ transplant recipients at the onset of cytomegalovirus disease and following treatment with intravenous ganciclovir or oral valganciclovir. J Clin Virol. 2013;58(1): 279-282.

81. Williams-Aziz SL, Hartline CB, Harden EA, et al. Comparative activities of lipid esters of cidofovir and cyclic cidofovir against replication of herpesviruses in vitro. Antimicrob Agents Chemother. 2005;49(9):3724-3733

82. Marty FM, Winston DJ, Chemaly RF, et al. A Randomized, Double-Blind, PlaceboControlled Phase 3 Trial of Ora Brincidofovir for Cytomegalovirus Prophylaxis in Allogeneic Hematopoietic Cell Transplantation. Biol Blood Marrow Transplant. 2019;25(2):369-381.

83. Wire MB, Morrison M, Anderson M, Arumugham T, Dunn J, Naderer $\mathrm{O}$. Pharmokinetics (PK) and Safety of Intravenous (IV) Brincidofovir (BCV) in Healthy Adult Subjects. Open Forum Infect Dis. 2017;4(Suppl 1):S311.

84. Becerra A, Gibson L, Stern LJ, Calvo-Calle JM. Immune response to HHV-6 and implications for immunotherapy. Curr Opin Virol. 2014;9:154-161.

85. Tzannou I, Papadopoulou A, Naik S, et al Off-the-Shelf Virus-Specific T Cells to Treat BK Virus, Human Herpesvirus 6 Cytomegalovirus, Epstein-Barr Virus, and Adenovirus Infections After Allogeneic Hematopoietic Stem-Cell Transplantation. J Clin Oncol. 2017;35(31):3547-3557.

86. Ishiyama K, Katagiri T, Ohata K, et al. Safety of pre-engraftment prophylactic foscarne administration after allogeneic stem cell transplantation. Transpl Infect Dis. 2012;14 (1):33-39

87. Ogata M, Satou T, Inoue Y, et al. Foscarnet against human herpesvirus (HHV)-6 reactivation after allo-SCT: breakthrough HHV-6 encephalitis following antiviral prophylaxis. Bone Marrow Transplant. 2013;48(2):257264.

88. Ogata M, Takano K, Moriuchi Y, et al. Effects of Prophylactic Foscarnet on Human Herpesvirus-6 Reactivation and Encephalitis in Cord Blood Transplant Recipients: A Prospective Multicenter Trial with an Historical Control Group. Biol Blood Marrow Transplant. 2018;24(6):1264-1273.

89. Ogata M, Satou T, Kawano R, et al. Plasma HHV-6 viral load-guided preemptive thera- py against HHV-6 encephalopathy after allogeneic stem cell transplantation: a prospective evaluation. Bone Marrow Transplant. 2008;41(3):279-285

90. Ishiyama K, Katagiri T, Hoshino T, Yoshida T, Yamaguchi M, Nakao S. Preemptive therapy of human herpesvirus- 6 encephalitis with foscarnet sodium for high-risk patients after hematopoietic SCT. Bone Marrow Transplant. 2011;46(6):863-869.

91. Zerr DM, Gupta D, Huang ML, Carter R Corey L. Effect of antivirals on human herpesvirus 6 replication in hematopoietic stem cell transplant recipients. Clin Infect Dis. 2002;34(3):309-317

92. Ljungman $\mathrm{P}, \mathrm{Dahl} \mathrm{H}, \mathrm{Xu} \mathrm{YH}$, Larsson $\mathrm{K}$ Brytting M, Linde A. Effectiveness of ganciclovir against human herpesvirus- 6 excreted in saliva in stem cell transplant recipients. Bone Marrow Transplant 2007; 39(8):497 499

93. Vu T, Carrum G, Hutton G, Heslop HE Brenner MK, Kamble R. Human her pesvirus-6 encephalitis following allogeneic hematopoietic stem cell transplantation. Bone Marrow Transplant. 2007;39(11):705 709

94. Ljungman P, de la Camara R, Cordonnier C, et al. Management of CMV, HHV-6, HHV-7 and Kaposi-sarcoma herpesvirus (HHV-8) infections in patients with hematological malignancies and after SCT. Bone Marrow Transplant. 2008;42(4):227-240.

95. Schmidt-Hieber M, Schwender J, Heinz WJ et al. Viral encephalitis after allogeneic stem cell transplantation: a rare complication with distinct characteristics of different causative agents. Haematologica. 2011;96(1):142-149.

96. Denes E, Magy L, Pradeau K, Alain S Weinbreck P, Ranger-Rogez S. Successful treatment of human herpesvirus 6 encephalomyelitis in immunocompetent patient. Emerg Infect Dis. 2004;10(4):729731.

97. Pohlmann C, Schetelig J, Reuner U, et al Cidofovir and foscarnet for treatment of human herpesvirus 6 encephalitis in a neutropenic stem cell transplant recipient. Clin Infect Dis. 2007;44(12):e118-e120.

98. Hill JA, Zerr DM. Human herpesvirus 6A 6B, 7 and 8 infections After Hematopoietic Stem Cell Transplantation. In: Ljungman $\mathrm{P}$, Snydman D, Boeckh M, editors. Switzerland: Springer International. 2016. pp.547-562.

99. Hill JA, Zerr DM. Roseoloviruses in trans plant recipients: clinical consequences and prospects for treatment and prevention trials. Curr Opin Virol. 2014;9:53-60 